\section{Screening and Selection of Twenty Iranian Wheatgrass Genotypes for Tolerance to Salinity Stress during Seed Germination and Seedling Growth Stage}

\author{
Mohamad-Hossein Sheikh-Mohamadi, Nematollah Etemadi', \\ and Ali Nikbakht \\ Department of Horticulture, College of Agriculture, Isfahan University of \\ Technology, Isfahan 84156-83111, Iran
}

\author{
Mostafa Farajpour \\ Department of Agronomy and Plant Breeding, College of Abouraihan, \\ University of Tehran, Tehran 3391653755, Iran
}

\section{Mostafa Arab \\ Department of Horticultural Sciences, College of Abouraihan, University of Tehran, Tehran 3391653755, Iran}

\section{Mohammad Mahdi Majidi \\ Department of Agronomy and Plant Breeding, College of Agriculture, Isfahan University of Technology, Isfahan 84156-83111, Iran}

Additional index words. antioxidant defense system, crested wheatgrass, desert wheatgrass, germination, tall wheatgrass, salinity stress, turfgrass

\begin{abstract}
Desert wheatgrass (Agropyron desertorum L.), tall wheatgrass (Agropyron elongatum L.), and crested wheatgrass (Agropyron cristatum L.) are native cool-season grass species that exhibit potential as a low-input turfgrass. An increased understanding of the biochemical and physiological responses of wheatgrass species and genotypes to salt stress conditions is important for developing genotypes with enhanced tolerance to salinity. The objective of this study was to characterize the physiological and antioxidative properties in 20 Iranian wheatgrass genotypes and to observe their responses to salinity stress during seed germination and seedling growth stage. A completely randomized factorial design was used with two types of factors, four levels of salinity $(0,50,100$, and $150 \mathrm{~mm}$ of $\mathrm{NaCl})$, wheatgrass genotypes, and three replicates. In this experiment, the results demonstrated that salinity limits the germination of Iranian wheatgrass genotype seeds. The result of this study showed that among the wheatgrass genotypes, 'AD1', 'AD3,' 'AC6', and 'FA' took the shortest average time to germinate. Higher levels of final germination percentage (FGP) were observed in 'AD2', 'AD3', and 'AE5' under salinity stress than other genotypes throughout the experiment. During a prolonged period of study, 'AD1' had greater rate of germination (GR) than other genotypes. Out of the 21 genotypes, five genotypes ('AD1', 'AD2', 'AD3', 'AE5', and 'FA' genotypes) were in the range of "salinity tolerant genotypes" cluster. The 'AD1', 'AD2', 'AD3', 'AE5', and 'FA' genotypes generally performed better than other genotypes under salinity conditions, mainly through maintaining higher enzymatic activities such as superoxide dismutase (SOD) (EC 1.15.1.1), catalase (CAT) (EC 1.11.1.6), ascorbate peroxidase (APX) (EC 1.11.1.11) and peroxidase (POD) (EC 1.111.1.7), and nonenzymatic antioxidant activities by glutathione (GSH). The 'AD1', 'AD2', 'AD3', 'AE5', and 'FA' genotypes also had higher proline levels and more of total nonstructural carbohydrates (TNC) content, lower malondialdehyde (MDA) content, and lower hydrogen peroxide content $\left(\mathrm{H}_{2} \mathrm{O}_{2}\right)$.
\end{abstract}

The germination phase is an important and vulnerable stage in the life cycle of plants because establishment of the seedling and plant growth can be partly defined and seriously influenced by salinity ( $\mathrm{Hu}$ et al., 2012b). Salinity stress is becoming a main environmental factor limiting seed germination and seedling growth in arid and semiarid regions (Sekmen et al., 2012). Different levels of salinity stress can affect turfgrass adversely. These may include a series of morphological, physiological, and biochemical metabolic disorders caused either by an osmotic stress or by an ion toxic effect (Hasegawa et al., 2000).

Salinity stress can stimulate the formation of reactive oxygen species (ROS), such as singlet oxygen $\left({ }^{1} \mathrm{O}_{2}\right)$, hydrogen peroxide $\left(\mathrm{H}_{2} \mathrm{O}_{2}\right)$, and hydroxyl radicals $\left(\mathrm{OH}^{*}\right)$ (Fan et al., 2013). These ROS are known as molecular factors that damage the cellular components of proteins, enzymes, membrane lipids, pigments, and nucleic acids (Hameed et al., 2014). Plant survival under adverse conditions is a feedback of advanced changes in metabolism which can be detailed as the accumulation of protective compounds such as compatible osmolytes and antioxidants (Hu et al., 2012b). ROS can accumulate when the stage of seed germination is occurring and when seedling growth happens under stress conditions (Simlata et al., 2016).

According to the role of antioxidant defense system in cleaning the ROS levels during germination, these enzymes are mainly important for the thorough occurrence of germination (Yan, 2015). Plants are often characterized by developing enzymatic and nonenzymatic defense systems for ROS scavenging to avoid these oxidative damages (Etemadi et al., 2015). Enzymatic antioxidants include SOD, CAT, POD, and APX. Nonenzymatic antioxidants are GSH, glutathione reductase, and phenolic compounds (Jianga et al., 2012).

Turfgrass management under saline conditions is becoming a serious concern in arid and semiarid regions of the world (Dai et al., 2009). Using salt-tolerant turfgrass is deemed an efficient method to alleviate salinity problems. Grass species and genotypes vary in their responses to salinity stress, which contains changes in morphological, physiological, and biochemical aspects (Zhang and Rue, 2011; Zhang et al., 2012). This indicates identification and screening of turfgrass for genetic improvement of salinity tolerance can be an acceptable strategy (Mittova et al., 2003). The first step in the program of identification and screening for salinity tolerance in grasses is a conduct a germination examination (Serena et al., 2012).

Desert wheatgrass (Agropyron desertorum L.), tall wheatgrass (Agropyron elongatum L.), and crested wheatgrass (Agropyron cristatum L.) are cool-season perennial grasses with strong tolerance to abiotic stress and accordingly, they are capable of growing in arid and semiarid climates (Bayat et al., 2016; Gunnel et al., 2010). This genus of wheatgrass is potentially a low-input turf because it is strongly tolerant against drought, salinity, low temperature, disease, and pests (Shana and Liagna, 2010; Sheikh-Mohamadi et al., 2017a). Until now, no information exists about Iranian wheatgrass genotypes regarding their potentials of tolerance to salinity during seed germination and seedling growth stage. Understanding the physiological and biochemical mechanism of turfgrass 
salinity tolerance is important for breeders if they are to develop salt-tolerant genotypes of turfgrass. Accordingly, practitioners can improve turfgrass quality under salinity stress if the correct genotypes are used for cultivation. Our objectives were to investigate osmotic adjustment and antioxidant capacity as indices that set an array of contrast among the
20 Iranian wheatgrass genotypes evaluated in this study. The ultimate aim was to compare their tolerance to salinity. The genotypes were initially categorized as the Iranian desert wheatgrass, tall wheatgrass, and crested wheatgrass, and the experiments were conducted during their seed germination and seedling growth stage.

\section{Materials and Methods}

Plant material and seed collection site. The experimental material was comprised of 20 native wheatgrass genotypes, including eight genotypes of Iranian desert wheatgrass (Agropyron desertorum L.), six genotypes of Iranian tall wheatgrass (Agropyron

Table 1. Geographical origin of Iranian wheatgrass genotypes and tall fescue (control).

\begin{tabular}{|c|c|c|c|c|c|c|c|}
\hline Code & Species & Region & Longitude (E) & Latitude $(\mathrm{N})$ & Altitude (m) & $\begin{array}{l}\text { Avg annual } \\
\text { temp }\left({ }^{\circ} \mathrm{C}\right)\end{array}$ & $\begin{array}{c}\text { Annual } \\
\text { rainfall }(\mathrm{mm} / \mathrm{yr})\end{array}$ \\
\hline$\overline{\mathrm{AD} 1}$ & Agropyron desertorum $\mathrm{L}$. & Fereidan-Isfahan & $50.1241^{\circ}$ & $32.9401^{\circ}$ & 2,290 & 9 & 505.5 \\
\hline AD2 & & Ardakan-Yazd & $54.0086^{\circ}$ & $32.3082^{\circ}$ & 1,035 & 19.8 & 69 \\
\hline AD3 & & Shahrud-Semnan & $55.0163^{\circ}$ & $36.4062^{\circ}$ & 1,380 & 14.1 & 161.5 \\
\hline AD4 & & Darab-Shiraz & $54.3100^{\circ}$ & $28.5400^{\circ}$ & 1,180 & 20.4 & 176.2 \\
\hline AD5 & & Mobarakeh-Isfahan & $52.5132^{\circ}$ & $31.8427^{\circ}$ & 1,690 & 24.8 & 192.6 \\
\hline AD6 & & Shahrekord-Chaharmahal \& Bakhtiary & $50.8769^{\circ}$ & $32.3282^{\circ}$ & 2,060 & 21.8 & 267.9 \\
\hline AD7 & & Boldaji-Chaharmahal \& Bakhtiari & $51.0300^{\circ}$ & $31.5600^{\circ}$ & 2,220 & 20.5 & 264.5 \\
\hline AD8 & & Malayer-Hamadan & $48.8146^{\circ}$ & $34.3020^{\circ}$ & 1,725 & 12.2 & 302.1 \\
\hline AE1 & Agropyron elengatum L. & Geydar-Zanjan & $48.5938^{\circ}$ & $36.1203^{\circ}$ & 2,775 & 11.5 & 420 \\
\hline AE2 & & Save-Markazi & $50.0136^{\circ}$ & $35.6980^{\circ}$ & 998 & 16.6 & 223.5 \\
\hline AE3 & & Aligudarz- Lorestan & $49.6962^{\circ}$ & $33.4050^{\circ}$ & 2,100 & 11.6 & 264.2 \\
\hline AE4 & & Paveh-Kermanshah & $46.3553^{\circ}$ & $35.0430^{\circ}$ & 1,540 & 12.5 & 674 \\
\hline AE5 & & Jiroft-Kerman & $57.7372^{\circ}$ & $28.6751^{\circ}$ & 720 & 23.5 & 81 \\
\hline AE6 & & Kuhin-Qazvin & $49.6598^{\circ}$ & $36.3716^{\circ}$ & 1,527 & 13.1 & 304.7 \\
\hline $\mathrm{AC} 1$ & Agropyron cristatum L. & Hashtgerd-Alborz & $50.6846^{\circ}$ & $35.9614^{\circ}$ & 1,175 & 14.6 & 377 \\
\hline $\mathrm{AC} 2$ & & Arak-Markazi & $49.7013^{\circ}$ & $34.0954^{\circ}$ & 1,750 & 13.9 & 311 \\
\hline $\mathrm{AC} 3$ & & Urmia-Azerbaijan & $45.0433^{\circ}$ & $37.3309^{\circ}$ & 1,330 & 10.6 & 555 \\
\hline $\mathrm{AC} 4$ & & Takestan-Qazvin & $49.7013^{\circ}$ & $36.0721^{\circ}$ & 1,260 & 18.1 & 350 \\
\hline $\mathrm{AC} 5$ & & Damavand-Tehran & $52.0631^{\circ}$ & $35.5721^{\circ}$ & 1,903 & 12.1 & 149 \\
\hline AC6 & & Sabzevar-Khorasan Razavi-Iran & $57.6678^{\circ}$ & $36.2152^{\circ}$ & 977 & 18.2 & 330 \\
\hline FA & Festuca arundinacea L. & - & - & - & - & - & - \\
\hline
\end{tabular}
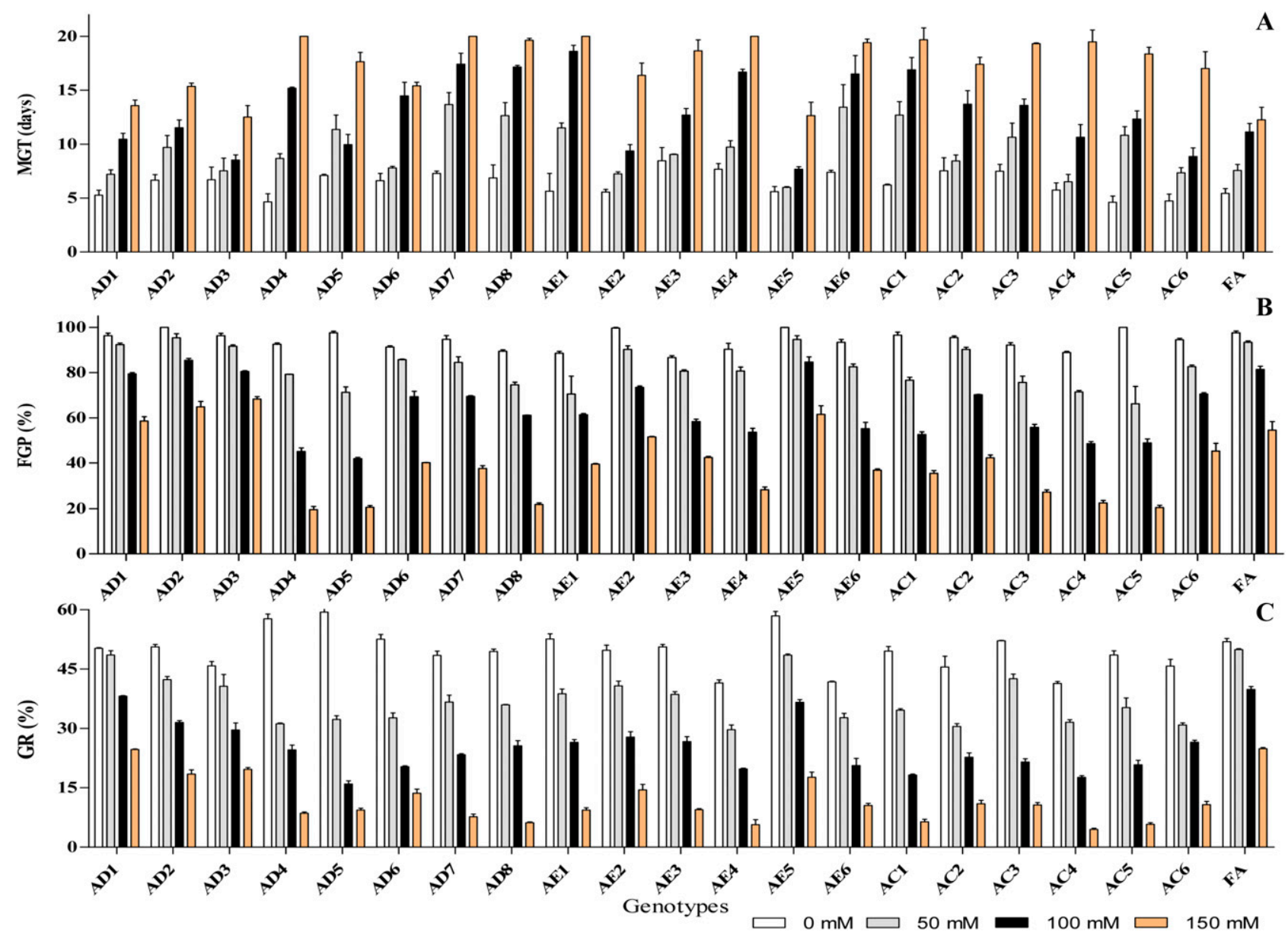

Fig. 1. Effect of salinity stress on mean germination time (MGT, A), final germination percentage (FGP, B), and rate of germination (GR, C) of 21 plants including 20 Iranian wheatgrass genotypes (AD1 to AC6) and tall fescue (FA). 
elongatum L.), and six genotypes of Iranian crested wheatgrass (Agropyron cristatum L.) (Table 1). Tall fescue (Festuca arundinacea L.) cultivar Van Gogh (relatively stress tolerant) was used as control treatment. Wheatgrass genotypes were collected in Sept. 2015 from 20 sites in Iran. All seed samples were kept at a constant $4{ }^{\circ} \mathrm{C}$ temperature at the Turfgrass Seed Testing center, Department of Horticulture at Isfahan University of Technology, Isfahan, Iran. Seeds were disinfected following the protocol of $8 \%$ sodium hypochlorite $(\mathrm{NaClO})$ for 10 min to prevent fungal attack and rinsed thoroughly with deionized water (Zhang and Rue, 2011). Preliminary investigation using different levels of light ( $24 \mathrm{~h}$ dark $/ 24 \mathrm{~h}$ light, 16:8 h light/dark, and 12-h light/dark cycle) and different temperatures regimes $(4,16,24$, and $32{ }^{\circ} \mathrm{C}$ ) the results indicated that optimized conditions for germination of Iranian wheatgrass genotypes seeds occurred at $24{ }^{\circ} \mathrm{C}$ and $16: 8 \mathrm{~h}$ light/dark, with a germination percentage nearly being $94 \%$. Before the germination test began, Iranian wheatgrass genotypes seeds were tested for seed viability, by methods of tetrazolium test (TTC test) (AOSA, 2000). Three replications of 30 seeds were used to test viability using tetrazolium solution (2, 3, 5-triphenyltetrazolium chloride). Accordingly, seeds were longitudinally cross-sectioned through the embryo and immersed in a $0.1 \%$ TTC solution at $30{ }^{\circ} \mathrm{C}$ for $24 \mathrm{~h}$ in the dark. Afterward, the cut seeds were tested for pink staining (Chanyengaa et al., 2012).

Germination and seedling growth study. Iranian wheatgrass genotypes were germinated in solutions included distilled water $0,50,100$, and $150 \mathrm{~mm}$ of $\mathrm{NaCl}$, corresponding to $0,0.2,0.4$, and $0.6 \mathrm{MPa}$ osmotic potential, respectively (López Colomba et al., 2013). Germination and seedling growth test were conducted in a programmed incubator under the controlled conditions: $16: 8 \mathrm{~h}$ light/dark cycle $\left(60 \mu \mathrm{mol} \cdot \mathrm{m}^{-2} \cdot \mathrm{s}^{-1}\right)(4000 \mathrm{~lx})$ each day for $20 \mathrm{~d}$ at temperatures of $24{ }^{\circ} \mathrm{C}$, and petri dishes were sealed with polyethylene sheets to prevent evaporation. During testing, contamination was not found. For each treatment, 100 seeds were used with four replicates each. The number of germinated seeds was recorded three times a week for $20 \mathrm{~d}$. A seed was considered as a germinated seed if the radicle or coleoptile had emerged and grown more than $2 \mathrm{~mm}$ in length. Indices of seed germination and seedling growth were calculated as follows: the values of final germination were obtained as the percentage of the total number of germinated seeds over the number of total seeds after $20 \mathrm{~d}$ (Dai et al., 2009). Final germination percentage is described by FGP $(\%)=100 \frac{\Sigma n}{20}$. The mean germination time (MGT) was calculated as $\mathrm{MGT}=\Sigma i(n i \times d i) / N$; where $n i$ is the number of seeds germinated at day $i$ after sowing, di is the time between the beginning of the experiment and the end of a particular interval of measurement, and $N$ is the total number of germinated seeds (Zhang, 2012). A modified Timson index of germination velocity $=\Sigma G / t$ was used for estimating the GR, where " $G$ " is germination percentage after every $48 \mathrm{~h}$ and " $t$ " is the total germination period (20 d) (Hameed et al., 2014). Radicle length and plumule length (RL and PL) and seedling fresh (RFW and PFW) and dry weight (RDW and PDW) were recorded. The seedlings were dried at $75^{\circ} \mathrm{C}$ for $\approx 48 \mathrm{~h}$, and seedling dry weight was measured (Colomba et al., 2013).

Hydrogen peroxide contents $\left(\mathrm{H}_{2} \mathrm{O}_{2}\right)$ and $M D A$ content. Wheatgrass genotypes seedlings samples were ground fine using liquid $\mathrm{N}_{2}$ in ice-chilled mortar and pestle and homogenized in 4\% ice-cold trichloro acetic acid. Homogenate was then centrifuged at $15,000 \mathrm{~g}$ for $15 \mathrm{~min}$ at $5{ }^{\circ} \mathrm{C}$. Supernatant was used for the calculated of hydrogen peroxide content $\left(\mathrm{H}_{2} \mathrm{O}_{2}\right.$; Zhou et al., 2005) and MDA content (Heath and Parker, 1968).

Proline content, TNC, and GSH content. Proline content was determined in $90 \%$ ethanol extracts from wheatgrass genotypes seedlings samples. After centrifuged at $19,000 \mathrm{~g}$ for $15 \mathrm{~min}$, the supernatant was stored at $5{ }^{\circ} \mathrm{C}$ and proline content determined according to the method described by Bates et al. (1973) with some modifications. TNC content was measured using the method of Fry et al. (1993) with some modifications and expressed as $0.2 \mathrm{~g}$ of wheatgrass genotypes seedlings samples. The reaction solution absorbance was read at $515 \mathrm{~nm}$ by a spectrophotometer. GSH content was measured using the method of Griffith (1980) with some modifications and expressed as $0.5 \mathrm{~g}$ of wheatgrass genotypes seedlings samples. Absorbance was calculated at $412 \mathrm{~nm}$, and the GSH content was calculated by using the standard curve.

Antioxidant enzymes. Exactly $0.4 \mathrm{~g}$ of wheatgrass genotypes seedlings was ground in $5 \mathrm{~mL}$ of $50 \mathrm{~mm}$ phosphatebuffer ( $\mathrm{pH} 7.6)$ at $5{ }^{\circ} \mathrm{C}$ then centrifuged at $14,000 \mathrm{~g}$ for $14 \mathrm{~min}$. The supernatant was gathered for assays of enzyme activities. Measurements were directed at conducting extractions and assays of different antioxidant enzymes, including APX activity, SOD activity, CAT activity, and POD activity, which were done according to the methods described by Han et al. (2008) and Zhou et al. (2005).

Data analyses. We used a completely randomized factorial design with two types of factors, four levels of salinity, wheatgrass genotypes, and three replicates. The data were subjected to analysis of variance (ANOVA) using SAS software (SAS institute Cary, NC, 1988). In addition, the mean values of SEM were compared using least significant difference test. Cluster analysis was performed to differentiate the genotypes according to the unweighted pair group method with arithmetic mean method. The cluster analysis and principle component analysis (PCA) were conducted using SPSS software for Windows 20.0 (SPSS Inc., Chicago, IL). Heat map of the correlations was conducted with MetaboAnalyst (http://www. metaboanalyst.ca/).

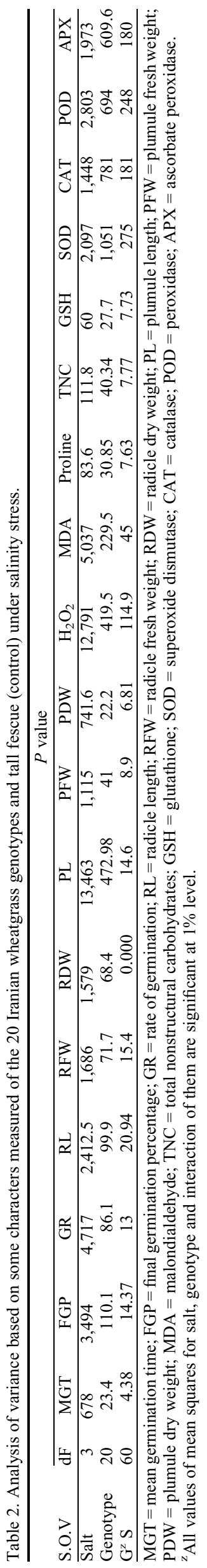




\section{Results and Discussion}

Effect of salinity stress on seeds germination. Viability was indicated by the TTC test. The results differed significantly among the various Iranian wheatgrass genotypes (data not shown). The results showed that seeds of 'AD1', 'AE1', 'AE6', and 'FA' used in the research had a high viability percentage $(\approx 98.0 \%)$. Seed germination is considered as the most sensitive stage of the plant life cycle (Sidari et al., 2008). Salinity stress may affect seed germination process through its complete inhibition or delay in the initiation of the germination and seedling establishment through the oxidative stress, osmotic stress, and ion toxicity (Freitas and Costab, 2014; Zhang et al., 2012). Salinity tolerance during seed germination and seedling growth stage is critical for the establishment of plants that can grow in Saline soils (Munns and Tester, 2008). In these experiments, our results demonstrated that salinity limits the germination of Iranian wheatgrass genotypes seeds. The result of this study showed that a direct relationship was observed between MGT and the increase in salinity concentration up to $150 \mathrm{~mm} \mathrm{NaCl}$ in all genotypes $(P \leq 0.01)$ (Fig. 1A). When salinity levels increased (50, 100, and $150 \mathrm{~mm} \mathrm{NaCl}$ ), MGT increased in all genotypes in comparison with the control condition (Fig. 1A). Among the wheatgrass genotypes, 'AD1', 'AD3', 'AE5', and 'FA' had the lowest MGT in this experiment (data not shown). A longer MGT under salinity stress was concurrent with delays in seed germination (Zeng et al., 2014). The result of ANOVA showed that there are significant differences among Iranian wheatgrass genotypes $(P \leq 0.01)$ when exposed to different salinity levels for FGP (Table 2). The highest FGP was observed for 'AD2', 'AD3', and 'AE5' genotypes. Salinity had significant effect on FGP $(P \leq 0.01)$, where increased levels of salinity reduced these traits in the all genotypes, and the rate of decline different between genotypes (Fig. 1B). At $50 \mathrm{~mm}$ $\mathrm{NaCl}$, 'AD2', 'AE5', and 'FA' genotypes showed the highest FGP $(\approx 94.0 \%)$ (Fig. 1B). As the salinity level increased to $100 \mathrm{~mm}$ $\mathrm{NaCl}$, FGP of 'AD2', and 'AE5' grew significantly higher $(\approx 85.0 \%)$ than the other grasses (Fig. 1B). The 'AD2', 'AD3', and 'AE5' indicated a high amount of FGP $(\approx 65.0 \%)$ when the salinity level was increased to $150 \mathrm{~mm} \mathrm{NaCl}$ (Fig. 1B). The results indicate that when salinity levels are increased, the effect can result in the reduction of GR in all of the genotypes. Nonetheless, among all, the 'AD1' was less damaged, and its GR was greater than that of the other genotypes. At $0 \mathrm{~mm} \mathrm{NaCl}$ treatment, the wheatgrass genotypes, 'AD4', 'AD5', and 'AE5' had the higher GR than the other genotypes (Fig. 1C). Seedlings of 'AD1', 'AE5', and 'FA' had higher GR than other genotypes under 50 and $100 \mathrm{~mm} \mathrm{NaCl}$ stress, as compared with the control (Fig. 1C). When salt concentrations were increased to $150 \mathrm{~mm}$ $\mathrm{NaCl}$, higher rates of GR were observed in 'AD1' and 'FA' (Fig. 1C). Salinity greatly affects germination and seedling growth, and finally reduces the germination percentage and rate. Furthermore, a delay in the initiation of seed germination process and seedling establishment is also expected, but variations in adaptive mechanisms may still exist in different species and genotypes (Camberato and Martin, 2004). When stress conditions are present, changes in the enzymes and hormones are commonly observed in the seed, and they can reduce the GR and FGP (Zhao et al., 2014). The maintenance of higher levels of FGP and GR under salinity stress is often associated with better salinity tolerance in genotypes (Dai et al., 2009).
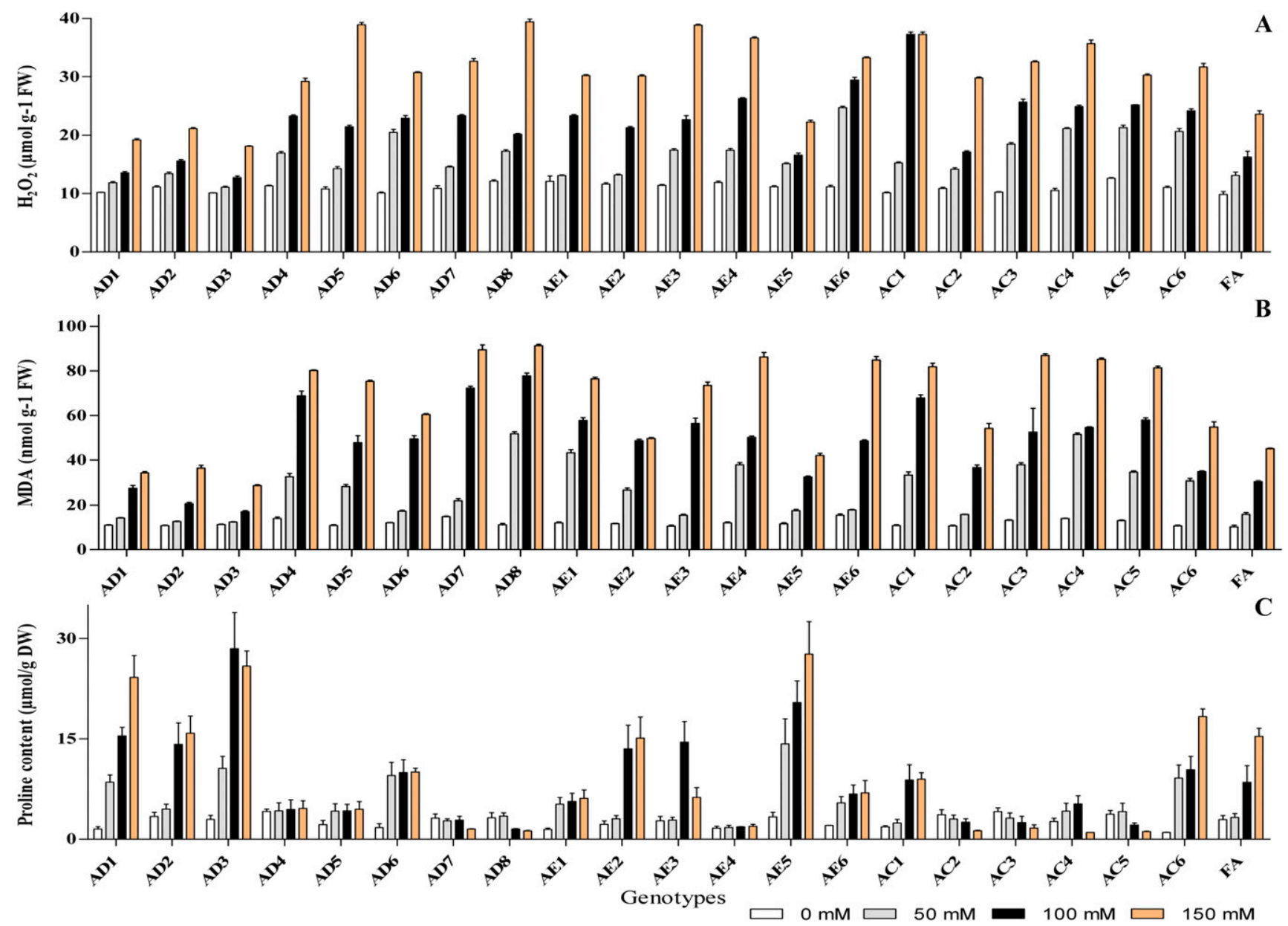

Fig. 2. Effect of salinity stress on hydrogen peroxide $\left(\mathrm{H}_{2} \mathrm{O}_{2}, \mathbf{A}\right)$ content, malondialdehyde (MDA, B) content, and proline content (C) of 21 plants including 20 Iranian wheatgrass genotypes (AD1 to AC6) and tall fescue (FA). 
Germination of seeds should occur uniformly for a successful establishment of turfgrass seedlings. High GR and FGP are indicators that there is a high potential for successful establishment (Lai et al., 2015; Zaher-Ara et al., 2016; Zhao et al., 2014). Prevention or delay of seed germination under salinity stress caused by an osmotic and oxidative stress and ion-toxicity effect, which limits the water uptake by seeds during germination with blocking membrane, or cytosolic antioxidants enzymes and hormones which leads to a series of physiological changes, contains changed function and structure of an enzyme and general reduction in hydrolytic capacity and metabolic activity and use of content of seeds reserve (Colomba et al., 2013; Hameed et al., 2014).

Effect of salinity stress on seedling growth. Results of this study show that fresh and dry weights and length of plumule and radicle were significantly affected by salt stress and cultivars $(P \leq 0.01)$ (Table 2$)$. The increase in severity of salinity stress reduced the amount of these traits in all genotypes. Tolerant to salinity during early seedling growth is important for the seedling establishment of grass that can grow in saline areas (Hu et al., 2012b). Of the Iranian wheatgrass genotypes, 'AD2', 'AD3', and 'AE5' had the highest RL, radicle fresh weight (RFW) and dry weight (RDW), whereas 'AC1' had the lowest of these traits. Among the 21 grasses genotypes, 'AD1', 'AD2', 'AD3', and 'FA' genotypes showed higher levels and 'AE6' genotypes showed lower levels of PL and plumule fresh weight (PFW) and plumule dry weight (PDW) (data not shown). The length of plumule and radicle are two important parameters that correspond with salt stress. Because the radicle grows to be in direct contact with the culture medium, water is absorbed from the culture medium and then the plumule supplies it to the rest of the plant (Cavallaroa et al., 2016; Laghmouchi et al., 2017). Accordingly, PL and RL provide an important instance whereby plants can be studied in how they respond to environmental stress (Mickky and Aldesuquy, 2017). The strongest possibility to grow in arid and saline areas occurs for plants that can maintain a longer plumule and radicle when exposed to stress conditions (Goatley et al., 2017).

Effect of salinity stress on physiological and biochemical traits. In an environment without stress, oxygen metabolism and oxygen toxicity occurs at a low level, and there is an ideal balance between production and elimination of ROS (Murillo-Amador et al., 2006). The balance between the production and elimination of ROS may be perturbed by a biotic and abiotic stresses (Meloni et al., 2003). Salinity stress promotes the accumulation of ROS, including ${ }^{1} \mathrm{O} 2, \mathrm{H}_{2} \mathrm{O}_{2}$, and $\mathrm{OH}^{*}$, which can cause oxidative damage to vital cellular components and cellular processes, such as membrane function, carbohydrates, proteins, enzymes, DNA, and nucleic acids (Kolenc et al., 2016; Sekmen et al., 2012), for example, ROS can affect the polyunsaturated fats and membrane lipids, leading to lipid peroxidation and MDA formation (Davey et al., 2005). The production of $\mathrm{H}_{2} \mathrm{O}_{2}$ in unstressed conditions $(0 \mathrm{~mm}$ $\mathrm{NaCl}$ ) remained relatively constant throughout the duration of the experiment in all genotypes (Fig. 2A). In all salinity treatments $(50,100$, and $150 \mathrm{~mm} \mathrm{NaCl})$, the drastic increase in $\mathrm{H}_{2} \mathrm{O}_{2}$ content was evaluated in all genotypes, whereas the lowest increase was observed in 'AD1', 'AD2', and 'AD3' genotypes (Fig. 2A). Plants that can maintain low levels of $\mathrm{H}_{2} \mathrm{O}_{2}$ content under salinity stress exposure will have the highest possibility of continued metabolic activity (Møller et al., 2007). The reduction of oxidative stress and maintaining the physical integrity of the cell membranes under salinity stress is
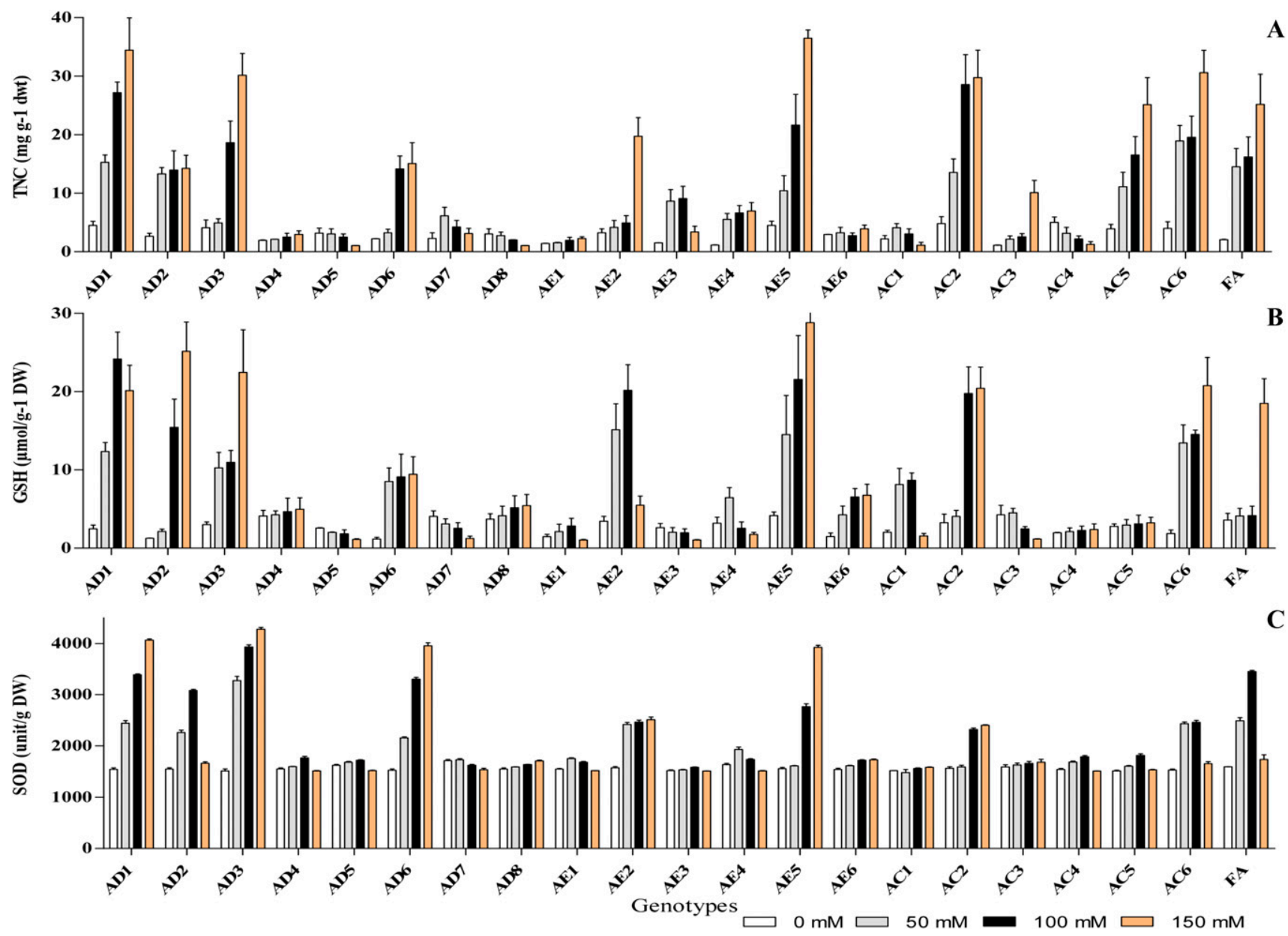

Fig. 3. Effect of salinity stress on total nonstructural carbohydrates (TNC, A) content, glutathione (GSH, B) content, and superoxide dismutase (SOD, C) activity of 21 plants including 20 Iranian wheatgrass genotypes (AD1 to AC6) and tall fescue (FA). 
considered one of the mechanisms in salinity tolerance (Hu et al., 2012a).

MDA is one of the final decomposition products when lipid peroxidation occurs in the plant cell membrane as it is caused by free radical damage and oxidative stress. Its accumulation is a sign of the extent to which oxidative damage occurs (Hernández and Almansa, 2002). The MDA has been widely used as a physiological indicator for the evaluation of plant tolerance to salinity stress, and it can be used as a tool for the differentiation of salt-tolerant and saltsensitive genotypes (Abid et al., 2016). Previous studies have reported that genotypes that exhibit lower levels of MDA content are more tolerant to salinity stress (Filek et al., 2012). Under various levels of salinity stress, the MDA production in all genotypes increased and the rate of increase was observed to be different between them (Fig. 2B). At $50 \mathrm{~mm} \mathrm{NaCl}$ treatment, the wheatgrass genotypes, and 'AE3' had the lowest MDA content (Fig. 2B). As the salinity level increased to $100 \mathrm{~mm} \mathrm{NaCl}$, MDA production in 'AD1', 'AD2', and 'AD3' significantly increased and showed the lowest MDA content in comparison with the other genotypes (Fig. 2B). When the salinity level was increased to $150 \mathrm{~mm} \mathrm{NaCl}$, the lowest rate of MDA content was observed in 'AD1', 'AD2', and 'AD3' (Fig. 2B). The results of Filek et al. (2012) suggested that the higher salt tolerance was associated with the lower MDA content. The variation in the levels of MDA content according to the different genotypes might have resulted from the ROS-mediated membrane lipid peroxidation calculated using MDA and differences in the roles of antioxidant protective enzymes in controlling the ROS level in seeds (Hu et al., 2012a). Stress-tolerant species and genotypes showed a better chloroplast structure under abiotic stress conditions with lower accumulation of $\mathrm{H}_{2} \mathrm{O}_{2}$ and MDA than stress-sensitive plants (Luna et al., 2008).

Mechanism of osmotic adjustment is considered as an important physiological response of stress adaptation in plant cells (Sekmen et al., 2012). It involves the accumulation of a wide range of osmotically active compounds including proline and TNC within the cell (Aranjuelo et al., 2011). Proline is an amino acid that is also considered as an important osmotically active compound. It plays an integral role in maintaining cell turgor and in protecting
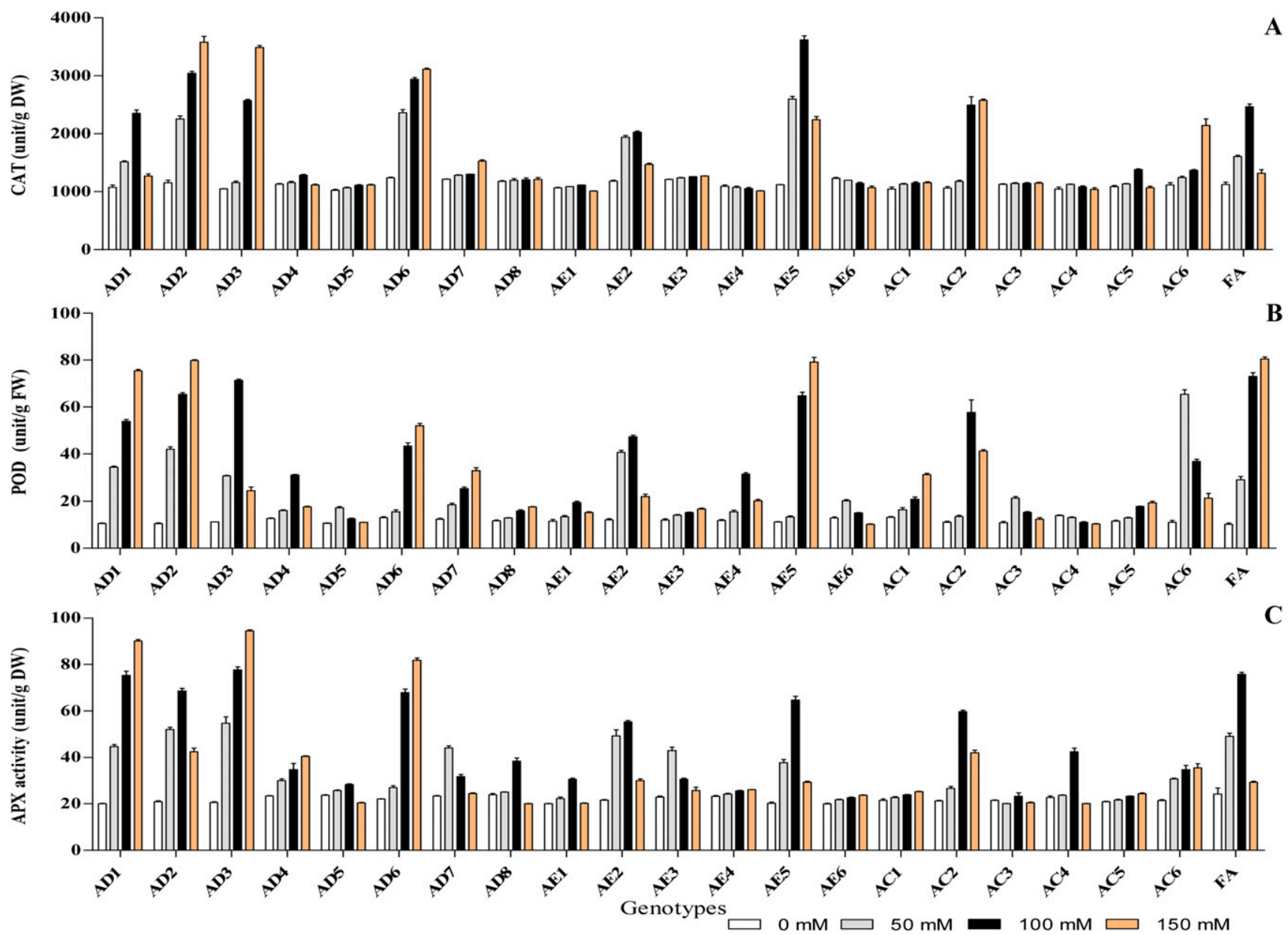

Fig. 4. Effect of salinity stress on catalase (CAT, A) activity, peroxidase (POD, B) activity, and ascorbate peroxidase (APX, C) activity of 21 plants including 20 Iranian wheatgrass genotypes (AD1 to AC6) and tall fescue (FA).

Table 3. Mean values of the characters studied based on cluster analysis.

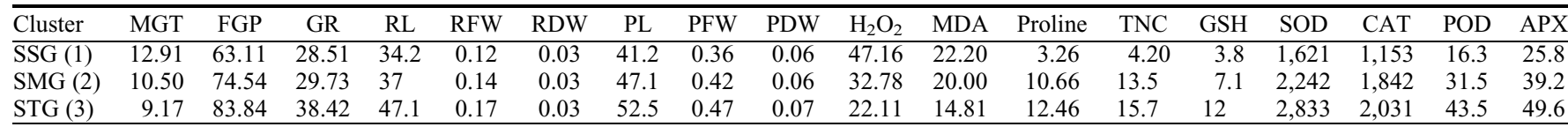

MGT = mean germination time; FGP = final germination percentage; $\mathrm{GR}=$ rate of germination; $\mathrm{RL}=$ radicle length; $\mathrm{RFW}=$ radicle fresh weight; $\mathrm{RDW}=$ radicle dry weight; $\mathrm{PL}=$ plumule length; $\mathrm{PFW}=$ plumule fresh weight; $\mathrm{PDW}=$ plumule dry weight; $\mathrm{MDA}=$ malondialdehyde; $\mathrm{TNC}=$ total nonstructural carbohydrates; $\mathrm{GSH}=$ glutathione; $\mathrm{SOD}=$ superoxide dismutase $\mathrm{CAT}=$ catalase $\mathrm{POD}=$ peroxidase; $\mathrm{APX}=$ ascorbate peroxidase; $\mathrm{SSG}=$ salinity sensitive genotypes; $\mathrm{SMG}=$ salinity moderate genotypes; $\mathrm{STG}=$ salinity tolerant genotypes. 
protein and membrane structures. It is antioxidant protective and helps with osmotic adjustment (Kima et al., 2016). Among the 20 experimental genotypes used in the present study, the seedling of 'AD3' and 'AE5' had the highest proline content, and 'AE4' had the lowest proline content. There was no change in the proline content in the 'AD4' and 'AE4' under salinity stress (Fig. 2C). The proline content in four of the genotypes ('AD1', 'AD2', 'AE2', and 'AE5') increased with elevating salinity stress levels $(0,50$, 100, and $150 \mathrm{~mm} \mathrm{NaCl}$ ) (Fig. 2C). Researchers previously showed that proline accumulation correlates with environmental stress. Increased proline content can naturally enhance plant tolerance, and such an observation has also been reported in several higher plants which, because of proline, become more tolerant to stress conditions (Pompeianoa et al., 2012). TNC content in plants include water-soluble (glucose, fructose, and sucrose) and storage (starch and fructan) sugars (Qian and Fu, 2005). Accumulation of TNC content under salinity stress acts in a manner that protects the cell by causing a balance in the osmotic strength of the cytosol. It further helps to protect tissue water, cellular membranes, and sustains turgor in leaves. It also assists in energy transport and energy storage (Huang and $\mathrm{Fu}$, 2000). Results showed that differences in TNC content were significant in different genotypes under different salinity level
$(P \leq 0.01)$ (Table 2$)$. The highest TNC content was observed in 'AD1', 'AE5', 'AC2', and 'AC6' genotypes. TNC content in 'AD1', 'AD3', 'AD6', 'AE5', 'AC2', 'AC5', 'AC6', and ' $F A$ ' seedlings increased with increasing salinity stress levels (Fig. 3A). The accumulation of TNC content in response to environmental stress has been reported in various grass species (Richie et al., 2001). Higher content of TNC in the grass could indicate a greater tolerant to stress condition. Several reports have indicated that an increase in TNC contents is associated with the improvement in tolerant to stress (DaCosta and Huang, 2006; Sheikh-Mohammadi et al., 2017b).

As a countermeasure against free radicals, plants have gradually developed highly efficient antioxidant defense system which acts to minimize and eliminate ROS-induced oxidative stresses. These defense systems are mostly comprised of antioxidant enzymes such as SOD, CAT, POD, APX, and nonantioxidant enzymes such as GSH which contribute to the prevention of subcellular damage (Simlata et al., 2016; Solimana et al., 2012). GSH is a hydrophilic nonantioxidant endogenous antioxidants, which keeps ROS from accumulating in cells and causing oxidative damage (Guo et al., 2006). In antioxidative defense mechanisms in grass, the balance between the ROS production and eliminates that determines the amount of oxidative stress (Demiral and Turkan,
Table 4. Principal component loadings for the traits measured on the 21 plants including 20 Iranian wheatgrass genotypes and tall fescue.

\begin{tabular}{llccc}
\hline & & \multicolumn{3}{c}{ Principal components } \\
\cline { 3 - 5 } Label & Characters & PC1 & PC2 & PC3 \\
\hline 1 & FGP & 0.91 & -0.22 & -0.14 \\
2 & MGT & -0.83 & -0.32 & 0.05 \\
3 & GR & 0.8 & -0.05 & 0.21 \\
4 & RL & 0.85 & -0.36 & 0.35 \\
5 & RFW & 0.86 & -0.32 & 0.34 \\
6 & RDW & 0.84 & -0.34 & 0.36 \\
7 & PL & 0.85 & 0.47 & 0.19 \\
8 & PFW & 0.83 & 0.47 & 0.19 \\
9 & PDW & -0.9 & 0.42 & 0.29 \\
10 & MDA & -0.9 & 0.19 & 0.27 \\
11 & $\mathrm{H}_{2} \mathrm{O}_{2}$ & -0.88 & 0.17 & 0 \\
12 & APX & 0.87 & 0 & -0.2 \\
13 & POD & 0.9 & -0.06 & -0.19 \\
14 & CAT & 0.82 & -0.03 & -0.24 \\
15 & SOD & 0.88 & -0.09 & -0.28 \\
16 & GSH & 0.86 & 0.12 & -0.27 \\
17 & Proline & 0.87 & 0.05 & -0.04 \\
18 & TNC & 0.79 & 0.05 & -0.19 \\
Eigenvalue & 13.25 & 1.24 & 1.02 \\
$\%$ of variance & 73.64 & 6.92 & 5.67 \\
Cumulative\% & 73.64 & 80.56 & 86.23 \\
\hline
\end{tabular}

MGT $=$ mean germination time; FGP $=$ final germination percentage; $\mathrm{GR}=$ rate of germination; $\mathrm{RL}=$ radicle length; $\mathrm{RFW}=$ radicle fresh weight; $\mathrm{RDW}=$ radicle dry weight; $\mathrm{PL}=$ plumule length; $\mathrm{PFW}=$ plumule fresh weight; PDW = plumule dry weight; $\mathrm{MDA}=$ malondialdehyde; $\mathrm{TNC}=$ total nonstructural carbohydrates; GSH = glutathione; $\mathrm{SOD}=$ superoxide dismutase $;$ CAT = catalase; $\mathrm{POD}=$ peroxidase APX $=$ ascorbate peroxidase The values higher than 0.5 are presented as bold significant.

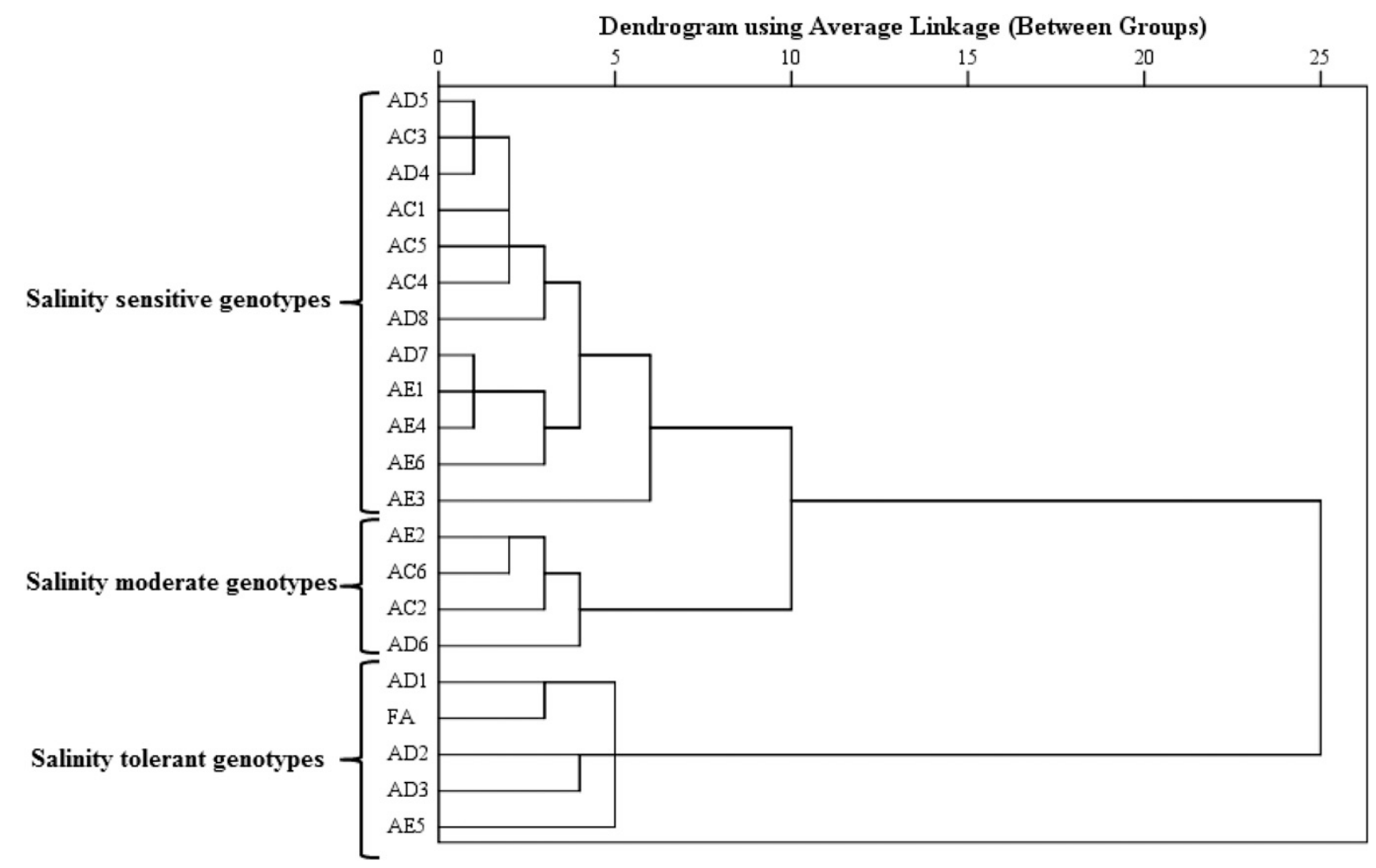

Fig. 5. Dendrogram generated based on traits measured on the 21 plants including 20 Iranian wheatgrass genotypes and tall fescue using the unweighted pair group method with arithmetic mean method. 
2005). Data in this study show that seedlings of 'AE2' and 'AE5' had higher GSH content than other genotypes when exposed to the lowest level of salinity (i.e., $50 \mathrm{~mm} \mathrm{NaCl}$ ) (Fig. 3B). When the stress level was increased to reach the highest level of salinity (i.e., $150 \mathrm{~mm} \mathrm{NaCl}$ ), the $\mathrm{GSH}$ content of 'AD2' and 'AE5' genotypes rose significantly to become higher than the other grasses (Fig. 3B). During the experiment, seedlings of 'AE5' Iranian wheatgrass genotypes had higher GSH content than other grasses. Higher content of GSH in the grass genotype could indicate a greater tolerant to stress condition (Taliaferro, 2003). Lu et al. (2008) found that an increase in GSH content directly correlates with increasing the drought stress in bermudagrass. SOD enzymes activity was observed to stay unchanged throughout the duration of the research in all genotypes when exposed to $0 \mathrm{~mm} \mathrm{NaCl}$ (Fig. 3C). However, under the 50, 100 , and $150 \mathrm{~mm} \mathrm{NaCl}$ stress conditions, the highest SOD enzymes activity were observed in 'AD3' (Fig. 3C). SOD is known as a major plant antioxidant, powerful enough to cope with ROS. It induces plant tolerant against environmental stresses (Liua and Chana, 2015). SOD causes the dismutation of $\mathrm{O}_{2}$ to $\mathrm{H}_{2} \mathrm{O}_{2}$ and to prevent $\mathrm{OH}^{*}$ formation (Sales et al., 2013). This study revealed that there was no change in the CAT enzymes activity in the 'AD8', 'AE1', 'AC1', 'AC3', and 'AC4' under salinity stress (Fig. 4A). Results show that CAT activity in 'AD1', 'AE5', and 'FA' increased when exposed to salinity stresses of 50 and $100 \mathrm{~mm} \mathrm{NaCl}$, but then decreased at $150 \mathrm{~mm} \mathrm{NaCl}$ (Fig. 4A). CAT plays an essential role in scavenging $\mathrm{H}_{2} \mathrm{O}_{2}$ toxicity, thereby acting protectively by transforming $\mathrm{H}_{2} \mathrm{O}_{2}$ to $\mathrm{H}_{2} \mathrm{O}$ and $\mathrm{O}_{2}$ which is subsequently followed by the elimination of ROS completely (Lu et al., 2009). At $50 \mathrm{~mm} \mathrm{NaCl}$ treatment, the wheatgrass genotypes 'AD5', 'AD1', and 'AC6' had higher POD enzyme activity (Fig. 4B). As salinity levels increase to reach $100 \mathrm{~mm} \mathrm{NaCl}$, POD activity of 'AD2', 'AD3', 'AE5', and 'FA' was significantly higher than the other grasses (Fig. 4B). When the salinity level was increased to $150 \mathrm{~mm} \mathrm{NaCl}$, the higher rate of POD enzymes activity was observed in 'AD1', 'AD2', 'AE5', and 'FA' (Fig. 4B). The activity of APX in 'AD1', 'AD3', 'AD4', and 'AD6' seedlings increased with elevating salinity stress (Fig. 4C). APX and POD are important antioxidant enzymes in the plant cycle because of their physiological role in transforming $\mathrm{H}_{2} \mathrm{O}_{2}$ to $\mathrm{H}_{2} \mathrm{O}$ and $\mathrm{O}_{2}$ and can scavenge or detoxify this ROS completely (Wang et al., 2009). Seed germination, seedling growth, and seedling establishment are parameters that are regularly weakened by increasing levels of environmental stress such as salinity stress (Hameed et al., 2014). Tolerance to abiotic stress or sensitivity in grass often correlates well with inherent antioxidant responses and cellular adjustments to oxidative stress

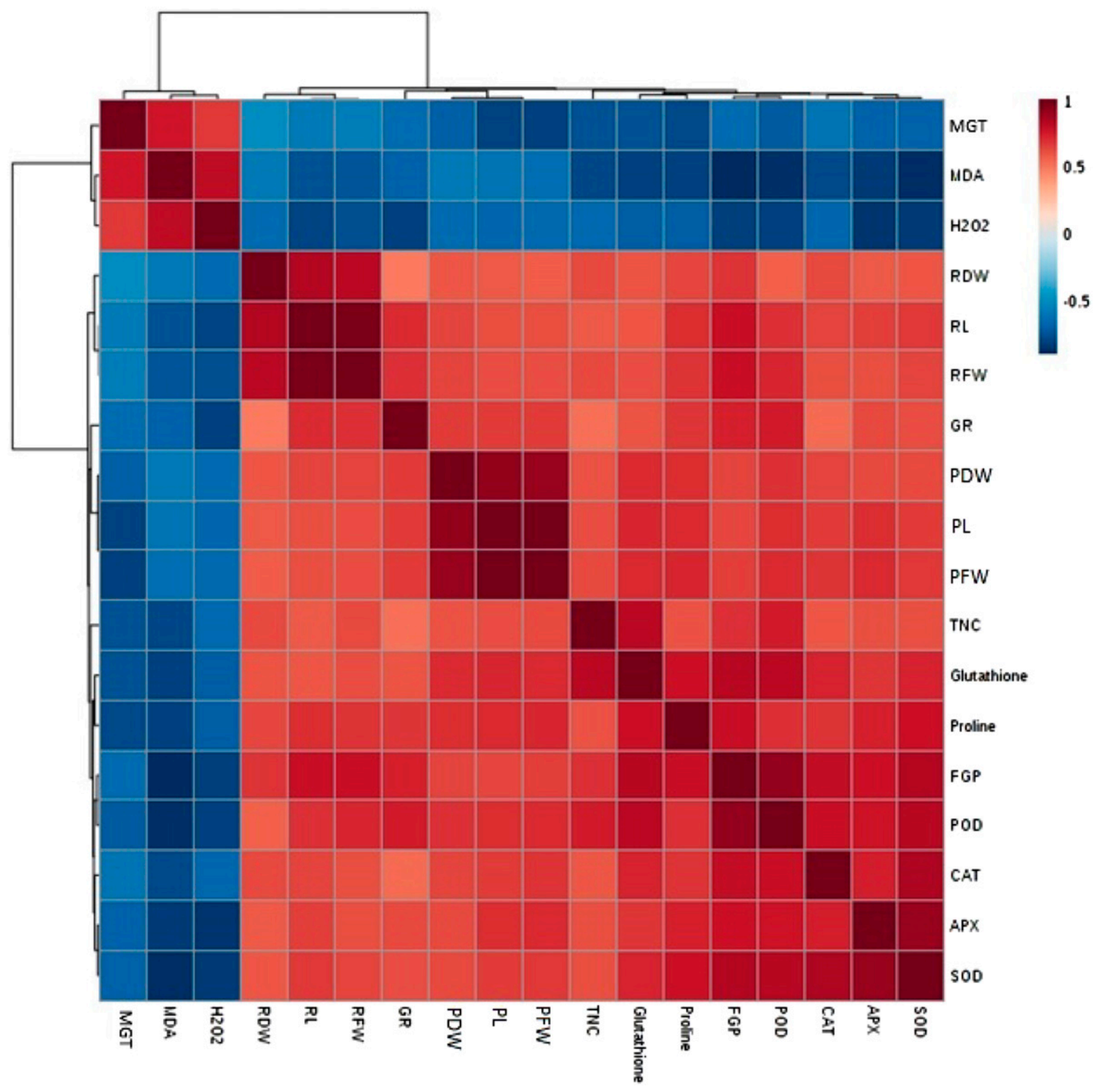

Fig. 6. Heat map of the correlations between the characters studied under drought stress of the 20 Iranian wheatgrass genotypes and tall fescue. 
(Amor et al., 2006). Our results indicate that the antioxidative defense mechanism is an essential component of salt tolerance in salttolerant wheatgrass genotypes. By comparing the response pattern of wheatgrass genotypes to salt stress and by comparing their antioxidant enzymes activities, results indicate that there is a significant genotypic difference among the genotypes with respect to salt exposure. Tolerant grass species and genotypes generally have a higher capacity to protect themselves from environmental stresses which induce oxidative damage. This can be achieved through the increase in antioxidant enzyme activity (Liua et al., 2012; Mhadhbi et al., 2011). Maintaining a high level of antioxidative enzyme activity can be likely effective for salinity tolerance by improving the antioxidant capacity as a powerful protection mechanism against oxidative stress. This has also been reported in several higher plants which happen to be tolerant under abiotic stress conditions. Xu et al. (2013) suggested that high levels of SOD, CAT, and APX can be considered as defense mechanisms in Kentucky bluegrass (Poa pratensis L.) and tall fescue (Festuca arundinacea $\mathrm{L}$.) under salinity stress conditions.

Cluster and PCA analysis. Cluster analysis was performed by considering all of the measured characteristics, which classified the genotypes into three clusters (Fig. 5). Out of the 21 genotypes, five genotypes ('AD1', 'AD2', 'AD3', 'AE5', and 'FA' genotypes) were in the "salinity tolerant genotypes" cluster. Three of the five genotypes of the "salinity tolerant genotypes" cluster came from desert wheatgrass. Therefore, desert wheatgrass genotypes were more tolerant among the wheatgrass species studied herein. The cluster exhibited the maximum values of some characteristics such as FGP, GR, RL, RFW, PL, PFW, PDW, APX, POD, CAT, SOD, proline, GSH, and TNC characters, and the minimum of MGT, MDA, and $\mathrm{H}_{2} \mathrm{O}_{2}$ characteristics (Table 3 ). The same condition was also observed in "salinity sensitive genotypes" cluster. Twelve genotypes were in this cluster. The mean value for RDW character in the three clusters was equal. Principle component analysis revealed that the first three components explained $86.23 \%$ of the variation in the genotypes under salinity stresses (Table 4). PC1 confirmed $73.64 \%$ of total variance. All measured characteristics correlated strongly with the first component; therefore, the PC1 was named "salinity stress." Among them, the FGP showed maximum correlation with the PC1 (0.91), followed by SDW (-0.9), MDA $(-0.9)$, and POD (0.9). Meanwhile, the SDW, MDA, $\mathrm{H}_{2} \mathrm{O}_{2}$, and MGT had negative correlations with $\mathrm{PC} 1$, whereas the other characteristics exhibited positive correlations with PC1. Because many measured characteristics had high correlation with the first component, it can be said that there were many correlations between other characteristics too (Fig. 6). The PC2 and PC3 confirmed $6.92 \%$ and $5.67 \%$ of the variance among the studied genotypes, respectively.

\section{Conclusions}

The results of this study show how genetic variation can cause differences in salinity tolerance among 21 grass genotypes. We observed that some wheatgrass genotypes are tolerant to salinity stress more than others. For all genotypes, FGP and GR were reduced, and MGT increased with increasing salinity stress. However, the magnitude of these effects differed between genotypes. Studying the salinity tolerance in genotypes was done using the data of all germination and seedling characteristics at all levels of drought stress. According to the results of cluster analysis, 'AD1', 'AD2', 'AD3', 'AE5', and 'FA' showed the highest salt tolerance. Our results suggest that the osmotic adjustment and antioxidant defense mechanisms depended on grass genotypes. It can be concluded that genotype is an essential component of salinity tolerance of wheatgrass. Salt-tolerant genotypes maintained higher levels of enzymatic (SOD, CAT, APX, and POD) and nonenzymatic (GSH) antioxidants activities, which caused further to accumulate compatible osmolytes (such as proline and TNC) under salinity conditions. Finally, it may be suggested that 'AD1', 'AD2', 'AD3', and 'AE5' are the strongest wheatgrass genotypes in terms of their tolerance to salt stress. However, longer-term experiments would be needed to validate salinity tolerance differences observed between these genotypes.

\section{Literature Cited}

Abid, M., Z.T. Tahir, A. Karim, Y. Liu, Y. Cui, R. Zahoor, D. Jiang, and T. Dai. 2016. Improved tolerance to post-anthesis drought stress by predrought priming at vegetative stages in droughttolerant and -sensitive wheat cultivars. Plant Physiol. Biochem. 106:218-227.

Amor, N.B., A. Jim'enez, W. Megdiche, M. Lundqvist, F. Sevilla, and C. Abdelly. 2006. Response of antioxidant systems to $\mathrm{NaCl}$ stress in the halophyte Cakile maritima. Physiol. Plant. 126:446-457.

AOSA. 2000. Tetrazlium testing handbook. Assn. Offic. Seed Analysts, Ithaca, NY.

Aranjuelo, I., G. Molero, G. Erice, J.C. Avice, and S. Nogu'es. 2011. Plant physiology and proteomics reveals the leaf response to drought in alfalfa (Medicago sativa L.). J. Expt. Bot. 62:111-123.

Bates, L.S., R.P. Waldren, and I.D. Teare. 1973. Rapid determination of free proline for waterstress studies. Plant Soil 39:205-207.

Bayat, H., H. Nemati, A. Tehranifar, and A. Gazanchian. 2016. Screening different crested wheatgrass (Agropyron cristatum (L.) Gaertner.) accessions for drought stress tolerance. Arch. Agron. 62:769-780.

Camberato, J.J. and S.B. Martin. 2004. Salinity slows germination of rough bluegrass. HortScience 39:394-397.

Cavallaroa, V., A.C. Barbera, C. Maucierib, G Gimmaa, C. Scalisi, and C. Patanè. 2016. Evaluation of variability to drought and saline stress through the germination of different ecotypes of carob (Ceratonia siliqua L.) using a hydrotime model. Ecol. Eng. 95:557-566.

Chanyengaa, T.F., C.J. Geldenhuysb, and G.W. Sileshic. 2012. Germination response and viability of an endangered tropical conifer Widdringtonia whytei seeds to temperature and light. S. Afr. J. Bot. 81:25-28.

Colomba, E.L., E. Tommasino, C. Luna, S. Griffa, E. Carloni, A. Ribotta, M. Quirog, and K. Grunberg. 2013. Differential salt-stress response during germination and vegetative growth in in vitro selected somaclonal mutants of Cenchrus ciliaris L. S. Afr. J. Bot. 87:157-163.

DaCosta, M. and B. Huang. 2006. Changes in carbon partitioning and accumulation patterns during drought and recovery for colonial bentgrass, creeping bentgrass, and velvet bentgrass. J. Amer. Soc. Hort. Sci. 131:484-490.

Dai, J., D.R. Huff, and M.J. Schlossberg. 2009 Salinity effects on seed germination and vegetative growth of greens-type Poа апnи a relative to other cool-season turfgrass species. Crop Sci. 49:696-703.

Davey, M.W., E. Stals, B. Panis, J. Keulemans, and R.L. Swennen. 2005. High throughput determination of malondialdehyde in plant tissues. Anal. Biochem. 347:201-207.

Demiral, T. and I. Turkan. 2005. Comparative lipid peroxidation, antioxidant systems and proline content in roots of two rice cultivars differing in salt tolerance. Environ. Exp. Bot. 53:247-257.

Etemadi, N., M.H. Sheikh-Mohammadi, A. Nikbakht, M.R. Sabzalian, and M. Pessarakli. 2015. Influence of trinexapac-ethyl in improving drought resistance of wheatgrass and tall fescue. Acta Physiol. Plant. 53:1-17.

Fan, H.F., C.X. Du, L. Ding, and Y.L. Xu. 2013. Effects of nitric oxide on the germination of cucumber seeds and antioxidant enzymes under salinity stress. Acta Physiol. Plant. 35:27072719.

Filek, M., S. Walas, H. Mrowiec, E. RudolphySko'rska, A. Sieprawska, and J. BiesagaKos'cielniak. 2012. Membrane permeability and micro- and macro-element accumulation in spring wheat cultivars during the short-term effect of salinity- and PEG-induced water stress. Acta Physiol. Plant. 34:985-995.

Freitas, F. and C.S.B. Costab. 2014. Germination responses to salt stress of two intertidal populations of the perennial glasswort Sarcocornia ambigua Ricardo. Aquat. Bot. 117:12-17.

Fry, J.D., S.N. Lang, R. Clifton, and F.P. Maier. 1993. Freezing tolerance and carbohydrate content of low temperature-acclimated and non-acclimated centipede grass. Crop Sci. 33:1051-1055.

Goatley, M., K. Hensler, and S. Askew. 2017. Cool-season turfgrass germination and morphological development comparisons at adjusted osmotic potentials. Crop Sci. 57:201208.

Griffith, O.W. 1980. Determination of glutathione and glutathione disulfide using glutathione reductase and 2-vinylpyridine. Anal. Biochem. 106:207-212.

Gunnel, K.L., T.A. Monaco, C.A. Call, and C.V. Ransom. 2010. Seedling interference and niche differentiation between crested wheatgrass and contrasting native great basin species. Rangeland Ecol. Manag. 63:443-449.

Guo, Z., W. Ou, S. Lu, and Q. Zhong. 2006. Differential responses of antioxidative system to chilling and drought in four rice cultivars differing in sensitivity. Plant Physiol. Biochem. 44:828-836

Hameed, A., A. Rasheeda, B. Gula, and M.A. Khanb. 2014. Salinity inhibits seed germination of perennial halophytes Limonium stocksi and Suaeda fruticosa by reducing water uptake and ascorbate dependent antioxidant system. Environ. Exp. Bot. 107:32-38. 
Han, L.B., G.L. Song, and X. Zhang. 2008. Preliminary observation of physiological responses of three turfgrass species to traffic stress. HortTechnology 18:139-143.

Hasegawa, P.M., R.A. Bressan, J.K. Zhu, and H.J. Bohnert. 2000. Plant cellular and molecular responses to high salinity. Annu. Rev. Plant Physiol. Plant Mol. Biol. 51:463-499.

Heath, R.L. and L. Parker. 1968. Photoperoxidation in isolated chloroplasts: I. Kinetics and stiochiometry of fatty acid peroxidation. Arch. Biochem. Biophys. 125:189-198.

Hernández, J.A. and M.S. Almansa. 2002. Shortterm effects of salt stress on antioxidant systems and leaf water relations of leaves. Physiol. Plant. 115:251-257.

Hu, L., H. Li, H. Pang, and J. Fu. 2012a. Responses of antioxidant gene, protein and enzymes to salinity stress in two genotypes of perennial ryegrass (Lolium perenne) differing in salt tolerance. J. Plant Physiol. 169:146-156.

Hu, M., Z. Shi, Z. Zhang, Y. Zhang, and H. Li. 2012b. Effects of exogenous glucose on seed germination and antioxidant capacity in wheat seedlings under salt stress. Plant Growth Regulat. $68: 177-188$.

Huang, B. and J. Fu. 2000. Photosynthesis, respiration, and carbon allocation of two coolseason perennial grasses in responses to surface soil drying. Plant Soil 227:17-26.

Jianga, J., M. Sua, L. Wanga, C. Jiaoa, Z. Suna, W. Chenga, F. Lia, and C. Wanga. 2012. Exogenous hydrogen peroxide reversibly inhibits root gravitropism and induces horizontal curvature of primary root during grass pea germination. Plant Physiol. Biochem. 53:84-93.

Kima, J., Y. Liub, X. Zhangb, B. Zhaoc, and K.L. Childsa. 2016. Analysis of salt-induced physiological and proline changes in 46 switchgrass (Panicum virgatum) lines indicates multiple response modes. Plant Physiol. Biochem. 105:203-212.

Kolenc, Z., D. Vodnik, S. Mandelc, B. Javornik, D. Kastelec, and A. Cerenak. 2016. Hop (Humulus lupulus L.) response mechanisms in drought stress: Proteomic analysis with physiology. Plant Physiol. Biochem. 105:67-78.

Laghmouchi, Y., O. Belmehdi, A. Bouyahya, N.S. Senhaji, and J.1. Abrini. 2017. Effect of temperature, salt stress and $\mathrm{pH}$ on seed germination of medicinal plant Origanum compactum. Biocatal. Agr. Biotechnol. 10:156-160.

Lai, L., Y. Tian, Y. Wang, X. Zhao, L. Jiang, J.M. Baskin, C.C. Baskin, and Y. Zheng. 2015. Distribution of three congeneric shrub species along an aridity gradient is related to seed germination and seedling emergence. AoB Plants 7:1-9.

Liua, X. and Z. Chana. 2015. Application of potassium polyacrylate increases soil water status and improves growth of bermudagrass (Cynodon dactylon) under droughtstress condition. Sci. Hort. 197:705-711.

Liua, Y., H. Du, X. He, B. Huang, and Z. Wang. 2012. Identification of differentially expressed salt-responsive proteins in roots of two perennial grass species contrasting in salinity tolerance. J. Plant Physiol. 169:117-126.

López Colomba, E., E. Tommasino, C. Luna, S. Griffa, E. Carloni, A. Ribotta, M. Quiroga, and K. Grunberg. 2013. Differential salt-stress response during germination and vegetative growth in in vitro selected somaclonal mutants of Cenchrus ciliaris L. S.A. J. Bot. 87:157-163.

Lu, S., W. Su, H. Li, and Z. Guo. 2009. Abscisic acid improves drought tolerance of triploid bermudagrass and involves $\mathrm{H}_{2} \mathrm{O}_{2-}$ and
NO-induced antioxidant enzyme activities. Plant Physiol. Biochem. 47:132-138.

Lu, S., Z. Wang, Y. Niu, Z. Guo, and B. Huang. 2008. Antioxidant responses of radiation-induced dwarf mutants of bermudagrass to drought stress. J. Amer. Soc. Hort. Sci. 133:360-366.

Luna, C., L. Garcı'a Seffino, C. Arias, and E. Taleisnik. 2008. Oxidative stress indicators as selection tools for salt tolerance in Chloris gayana. Plant Breed. 119:341-345.

Meloni, D.A., M.A. Oliva, C.A. Martinez, and J. Cambraia. 2003. Photosynthesis and activity of superoxide dismutase, peroxidase and glutathione reductase in cotton under salt stress. Environ. Exp. Bot. 49:69-76.

Mhadhbi, H., V. Fotopoulos, P.V. Mylona, M. Jebara, M.E. Aouani, and A.N. Polidoros. 2011. Antioxidant gene-enzyme responses in Medicago truncatula genotypes with different degree of sensitivity to salinity. Physiol. Plant. 141:201-214.

Mickky, B.M. and H.S. Aldesuquy. 2017. Impact of osmotic stress on seedling growth observations, membrane characteristics and antioxidant defense system of different wheat genotypes. EJBAS 4:47-54.

Mittova, V., M. Tal, M. Volokita, and M. Guy. 2003. Up-regulation of the leaf mitochondrial and peroxisomal antioxidative systems in response to salt-induced oxidative stress in the wild salt-tolerant tomato species Lycopersicon pennellii. Plant Cell Environ. 26:845-856.

Møller, I.M., P.E. Jensen, and A. Hansson. 2007. Oxidative modifications to cellular components in plants. Annu. Rev. Plant Biol. 58:459-481.

Munns, R. and M. Tester. 2008. Mechanisms of salinity tolerance. Annu. Rev. Plant Biol. 59:651-681.

Murillo-Amador, B., H.G. Jones, C. Kaya, R.L. Guilar, J.L. Garcia-Hernandez, E. Troyo-Dieguez, N.Y. Avila-Serrano, and E. Rueda-Puente. 2006. Effects of foliar application of calciumnitrate on growth and physiological attributes of cowpea (Vigna unguiculata L.) grown under salt stress. Environ. Exp. Bot. 58:188-196.

Pompeianoa, A., V. Gianninib, M. Gaetanic, F. Vitac, L. Guglielminettic, E. Bonarib, and M. Volterranica. 2012. Response of warm-season grasses to $\mathrm{N}$ fertilization and salinity. Sci. Hort. 177:92-98.

Qian, Y.L. and J.M. Fu. 2005. Response of creeping bentgrass to salinity and mowing management: Carbohydrate availability and ion accumulation. HortScience 40:2170-2174.

Richie, W.E., R.L. Green, and F. Merino. 2001. Trinexapacethyl does not increase total nonstructural carbohydrate content in leaves, crowns, and roots of tall fescue. HortScience 36:772-775.

Sales, C.R.G., R.V. Ribeiro, J.A.G. Silveira, E.C. Machado, M.O. Martins, and A.M.M.A. Lagôa. 2013. Superoxide dismutase and ascorbate peroxidase improve the recovery of photosynthesis in sugarcane plants subjected to water deficit and low substrate temperature. Plant Physiol. Biochem. 73:326-336.

Sekmen, H., I. Turkan, Z.O. Tanyolac, C. Ozfidan, and A. Dinc. 2012. Different antioxidant defense responses to salt stress during germination and vegetative stages of endemic halophyte Gypsophila oblanceolata bark. Environ. Exp. Bot. 77:63-76.

Serena, M., B. Leinauer, R. Sallenave, M. Schiavon, and B. Maier. 2012. Media selection and seed coating influence germination of turfgrasses under salinity. HortScience 47:116-120.

Shana, C. and Z. Lianga. 2010. Jasmonic acid regulates ascorbate and glutathione metabolism in Agropyron cristatum leaves under water stress. Plant Sci. 178:130-139.

Sheikh-Mohamadi, M.H., N. Etemadi, and A. Nikbakht. 2017a. Physiological responses of two cool-season grass species to trinexapacethyl under traffic stress. HortScience 52:99109.

Sheikh Mohammadi, M.H., N. Etemadi, M. Arab, M. Aalifar, M. Arab, and M. Pessarakli. 2017b. Molecular and physiological responses of Iranian Perennial ryegrass as affected by Trinexapac ethyl, Paclobutrazol and Abscisic acid under drought stress. Plant Physiol. Biochem. 111:129-143.

Sidari, M., C. Mallamaci, and A. Muscolo. 2008. Drought, salinity and heat differently affect seed germination of Pinus pinea. J. For. Res. 13:326-330.

Simlat, M., P. Ślęzak, M. Moś, M. Warchoł, E. Skrzypek, and A. Ptak. 2016. The effect of light quality on seed germination, seedling growth andselected biochemical properties of Stevia rebaudiana Bertoni. Sci. Hort. 211:295-304.

Solimana, W.S., M. Fujimoric, K. Tased, and S. Sugiyamaa. 2012. Heat tolerance and suppression of oxidative stress: Comparative analysis of 25 cultivars of the $\mathrm{C} 3$ grass Lolium perenne. Environ. Exp. Bot. 78:10-17.

Taliaferro, C.M. 2003. Bermudagrass (Cynodon (L.) Rich), p. 235-256. In: M.D. Casler and R.R. Duncan (eds.). Turfgrass biology, genetics, and breeding. Wiley, Hoboken, NJ.

Wang, W.B., Y.H. Kim, H.S. Lee, K.Y. Kim, X.P. Deng, and S.S. Kwak. 2009. Analysis of antioxidant enzyme activity during germination of alfalfa under salt and drought stresses. Plant Physiol. Biochem. 47:570-577.

Xu, R., M. Yamada, and H. Fujiyama. 2013. Lipid peroxidation and antioxidative enzymes of two turfgrass species under salinity stress. Pedosphere 23:213-222.

Yan, M. 2015. Seed priming stimulate germination and early seedling growth of Chinese cabbage under drought stress. S. Afr. J. Bot. 99:88-92.

Zaher-Ara, T., N. Boroomand, and M. SadatHosseini. 2016. Physiological and morphological response to drought stress in seedlings of ten citrus. Trees 30:985-993.

Zeng, Y.J., Y.R. Wang, C.C. Baskin, and J.M. Baskin. 2014. Testing seed germination responses to water and salinity stresses to gain insight on suitable microhabitats for restoration of cold desert shrubs. J. Arid Environ. 100: 89-92.

Zhang, H. 2012. Seed germination and early seedling growth of Cynanchum bungei decne (Asclepiadaceae) in response to photoperiod, temperature, and seed size. HortScience 47:1338-1341.

Zhang, Q., K. Rue, and S. Wang. 2012. Salinity effect on seed germination and growth of two warm-season native grass species. HortScience 47:527-530.

Zhang, Q.S.W. and K. Rue. 2011. Salinity tolerance of 12 turfgrasses in three germination media. HortScience 46:651-654.

Zhao, Y., Z. Lu, and L. He. 2014. Effects of salinealkaline stress on seed germination and seedling growth of Sorghum bicolor (L.). Moench. Biotechnol. Appl. Biochem. 173:1680-1691.

Zhou, B., Z. Guo, J. Xing, and B. Huang. 2005. Nitric oxide is involved in abscisic acidinduced antioxidant activities in Stylosanthes guianensis. J. Expt. Bot. 56:3223-3228. 